ARTICLE

\title{
Discovery of earth-abundant nitride
}

\section{semiconductors by computational screening and high-pressure synthesis}

Yoyo Hinuma ${ }^{1,2}$, Taisuke Hatakeyama ${ }^{3}$, Yu Kumagai ${ }^{4}$, Lee A. Burton ${ }^{3}$, Hikaru Sato ${ }^{3}$, Yoshinori Muraba ${ }^{4}$, Soshi limura ${ }^{3}$, Hidenori Hiramatsu ${ }^{3,4}$, Isao Tanaka, ${ }^{1,2}$, Hideo Hosono ${ }^{3,4}$ \& Fumiyasu Oba 1,2,3,4

Nitride semiconductors are attractive because they can be environmentally benign, comprised of abundant elements and possess favourable electronic properties. However, those currently commercialized are mostly limited to gallium nitride and its alloys, despite the rich composition space of nitrides. Here we report the screening of ternary zinc nitride semiconductors using first-principles calculations of electronic structure, stability and dopability. This approach identifies as-yet-unreported $\mathrm{CaZn} \mathrm{n}_{2} \mathrm{~N}_{2}$ that has earth-abundant components, smaller carrier effective masses than gallium nitride and a tunable direct bandgap suited for light emission and harvesting. High-pressure synthesis realizes this phase, verifying the predicted crystal structure and band-edge red photoluminescence. In total, we propose 21 promising systems, including $\mathrm{Ca}_{2} \mathrm{ZnN}_{2}, \mathrm{Ba}_{2} \mathrm{ZnN}_{2}$ and $\mathrm{Zn}_{2} \mathrm{PN}_{3}$, which have not been reported as semiconductors previously. Given the variety in bandgaps of the identified compounds, the present study expands the potential suitability of nitride semiconductors for a broader range of electronic, optoelectronic and photovoltaic applications.

\footnotetext{
${ }^{1}$ Department of Materials Science and Engineering, Kyoto University, Yoshida-Honmachi, Sakyo-ku, Kyoto 606-8501, Japan. ${ }^{2}$ Center for Materials Research by Information Integration, National Institute for Materials Science, 1-2-1 Sengen, Tsukuba 305-0047, Japan. ${ }^{3}$ Laboratory for Materials and Structures, Institute of Innovative Research, Tokyo Institute of Technology, 4259 Nagatsuta, Midori-ku, Yokohama 226-8503, Japan. ${ }^{4}$ Materials Research Center for Element Strategy, Tokyo Institute of Technology, 4259 Nagatsuta, Midori-ku, Yokohama 226-8503, Japan. Correspondence and requests for materials should be addressed to H.Hi. (email: h-hirama@lucid.msl.titech.ac.jp) or to F.O. (email: oba@msl.titech.ac.jp).
} 
S emiconductors are increasingly relied upon in modern society. Prototypical elemental semiconductors, Si and Ge, play principal roles in electronics and photovoltaics. Compound semiconductors including $\mathrm{GaAs}, \mathrm{GaP}$ and $\mathrm{GaN}$ have not only enhanced these applications, but also paved the way to optoelectronic devices, such as light-emitting diodes ${ }^{1}$. Current electronics also utilize oxide semiconductors in thin-film transistors $^{2}$, and semiconductor-based photocatalysts and photoelectrochemical cells are being developed, particularly for the electrolysis of water ${ }^{3,4}$. With such a variety of applications, the exploration of novel semiconducting materials has been a fundamentally and technologically important issue. Among the compound semiconductors, nitrides are attractive due to the abundant and environmentally benign nitrogen constituent. Many nitrides possess relatively high chemical stability at high temperature, which is advantageous for applications under severe environments such as power electronics. Moreover, bulk crystal and film growth techniques are well established, especially for group III nitrides. However, the currently commercialized nitride semiconductors are mostly limited to GaN and its based

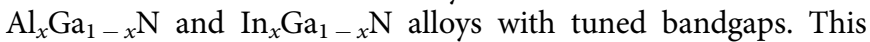
situation has stimulated experimental and computational searches of novel nitrides, for instance, spinel- $\mathrm{Si}_{3} \mathrm{~N}_{4}$ (ref. 5), cubic- $\mathrm{Zr}_{3} \mathrm{~N}_{4}$ (ref. 6), $\mathrm{ZnSnN}_{2}$ (ref. 7), $\mathrm{CuNbN}_{2}$ (ref. 8) and $\mathrm{LaWN}_{3}$ (ref. 9). In particular, recent developments of highthroughput first-principles screening based on prototype crystal structures and evolutionary algorithm structure searches have enabled the accelerated identification of a variety of previously unreported or uncharacterized semiconductors, including nitrides $^{8-20}$.

High carrier mobility is desirable or even mandatory, in most applications of semiconductors, and the effective mass is a relevant fundamental physical parameter. Group III nitrides in the wurtzite structure, especially $\mathrm{GaN}$ and $\mathrm{InN}$, have small electron effective masses due to spatially diffuse cation $s$-orbital contributions to their conduction bands. Moderate hole effective masses are also attained in the valence bands with mainly $\mathrm{N}-2 p$ characteristics. Technological uses for nitride semiconductors could be expanded if alternative materials with similar desirable electronic properties were found. Ideally, such alternatives should be environmentally benign and comprised of earth-abundant constituents. A chemical analogy to $\mathrm{GaN}$ and $\mathrm{InN}$ suggests that the nitrides composed of $\mathrm{Zn}, \mathrm{Ge}$ or $\mathrm{Sn}$ would be good candidates. In particular, hybridization between closed-shell $\mathrm{Zn}-3 d$ and $\mathrm{N}-2 p$ states in the valence band is expected to reduce hole effective masses in $\mathrm{Zn}$ nitrides. Indeed, a $\mathrm{Zn}$ binary nitride, $\mathrm{Zn}_{3} \mathrm{~N}_{2}$, possesses such a band structure ${ }^{21}$, but the fabrication of its high-quality film is still challenging, partly due to its small exothermic formation enthalpy $\left(-22.6 \mathrm{~kJ} \mathrm{~mol}^{-1}\right.$ or $-47 \mathrm{meV}$ per atom $)^{22}$. In addition, well-known ternary zinc nitride semiconductors are limited to a small number of systems, such as $\mathrm{LiZnN}$ (ref. 23), $\mathrm{ZnGeN}_{2}$ (ref. 24) and $\mathrm{ZnSnN}_{2}$ (ref. 7).

Here we report computational screening of ternary zinc nitrides using a combination of the prototype-based and evolutionary algorithm structure searches. Twenty-one promising semiconductors with small carrier effective masses are identified via systematic first-principles calculations of stability and electronic structure. The proposed nitrides include previously unreported $\mathrm{CaZn}_{2} \mathrm{~N}_{2}$ with earth-abundant components and a direct bandgap, which is synthesized by high-pressure methods. Alloy calculations indicate a bandgap capable of covering most of the visible light range. Native defect and dopant calculations also predict $p$ - and $n$-type dopability for $\mathrm{CaZn}_{2} \mathrm{~N}_{2}$ and the related $\mathrm{Ca}_{2} \mathrm{ZnN}_{2}$.

\section{Results}

Theoretical identification of ternary zinc nitride semiconductors. Systems of interest have been selected from 583 existing and hypothetical ternary zinc nitrides, which consist of various polymorphs of 125 chemical formulae. These candidate compounds are constructed using 52 prototype crystal structures, either reported in the Inorganic Crystal Structure Database (ICSD) ${ }^{25}$ or previously predicted theoretically ${ }^{15}$ (Supplementary Table 1). The considered structures are taken by $\mathrm{N}^{3-}$ compounds, that is, nitrides, involving two kinds of cations, at least one of that is divalent; those taken by azides, diazenides and pernitrides are excluded. The divalent cation is replaced with $\mathrm{Zn}$ (II) and the other is replaced with a cation of the same valence (Supplementary Table 2), which is expected to yield a closed-shell electronic structure and therefore exhibit a quantifiable bandgap. The cation species are not restricted to abundant elements at this stage because the electronic structure of compounds involving any element can provide useful information on the design of novel semiconductors. Subsequently, an evolutionary algorithm $^{12,26}$ is used to validate or update the most stable crystal structures. This allows us to overcome the limitations associated with relying on already reported crystal structures in the ICSD.

The screening is performed from various aspects: (i) the electronic structure, that is, bandgaps and effective masses; (ii) dynamic stability against lattice vibration; and (iii) thermodynamic stability against competing phases in the phase diagram. Here, not only thermodynamically stable phases, but also metastable phases with small positive formation energies $(<50$ $\mathrm{meV}$ per atom) are selected. This tolerance partly accommodates errors associated with the approximations used in first-principles calculations and the omission of temperature effects (Supplementary Method 1). Although metastable phases with higher formation energies may be grown by the use of high pressure, high temperature and/or non-equilibrium conditions, we prioritize the predictions of thermodynamically stable or slightly metastable compounds for the ease of the fabrication. Furthermore, the energetics of relevant native point defects and dopants is assessed to identify the dopability into $p$ type, $n$ type or both for promising compounds. Details of the screening and computational procedures are described in the Methods section and Supplementary Method 1.

Identified from the computational screening are 21 nitrides that are dynamically stable and thermodynamically stable/slightly metastable against competing phases (with formation energies that are $<50 \mathrm{meV}$ per atom), possess bandgaps and exhibit small effective masses for holes, electrons or both (smaller than $2 m_{0}$, where $m_{0}$ denotes the free-electron rest mass); their crystal structures, phonon densities of states, phase diagrams and electronic band structures are presented in Supplementary Figs 1-4 and Supplementary Table 3. Here, heavy holes are considered when the valence band maximum (VBM) is degenerate or nearly degenerate, as their dominant contributions to the electronic density of states near the VBM mean that heavy holes are most relevant to hole conduction. The bandgaps and effective masses of these nitrides are shown in Fig. 1, alongside those of $\mathrm{Zn}_{3} \mathrm{~N}_{2}$ and $\mathrm{GaN}$. Our screening identifies 11 nitrides that have not been reported in the ICSD, $\mathrm{Be}_{2} \mathrm{ZnN}_{2}$, $\mathrm{Mg}_{2} \mathrm{ZnN}_{2}, \quad \mathrm{CaZn}_{2} \mathrm{~N}_{2}, \mathrm{Zn}_{3} \mathrm{LaN}_{3}, \mathrm{ZnTiN}_{2}, \mathrm{ZnZrN}, \mathrm{ZnHfN}_{2}$, $\mathrm{Zn}_{2} \mathrm{VN}_{3}, \mathrm{Zn}_{2} \mathrm{NbN}_{3}, \mathrm{Zn}_{2} \mathrm{TaN}_{3}$ and $\mathrm{Zn}_{3} \mathrm{WN}_{4}$. It has also selected 10 already known nitrides, validating our computational methods and screening criteria: $\mathrm{LiZnN}$ (ref. 23), $\mathrm{Ca}_{2} \mathrm{ZnN}_{2}$ (ref. 27), $\mathrm{Sr}_{2} \mathrm{ZnN}_{2}$ (ref. 28), $\mathrm{Ba}_{2} \mathrm{ZnN}_{2}$ (ref. 28), $\mathrm{ZnSiN}_{2}$ (ref. 24), $\mathrm{ZnGeN}_{2}$ (ref. 24), $\mathrm{ZnSnN}_{2}$ (ref. 7) and $\mathrm{Zn}_{2} \mathrm{PN}_{3}$ (ref. 29) reported experimentally, and $\mathrm{NaZnN}$ and $\mathrm{KZnN}$ predicted theoretically ${ }^{15}$. We note that four of these known nitrides, that is, $\mathrm{Ca}_{2} \mathrm{ZnN}_{2}, \mathrm{Sr}_{2} \mathrm{ZnN}_{2}, \mathrm{Ba}_{2} \mathrm{ZnN}_{2}$ and $\mathrm{Zn}_{2} \mathrm{PN}_{3}$ have not, to our knowledge, been considered as semiconductors previously and 

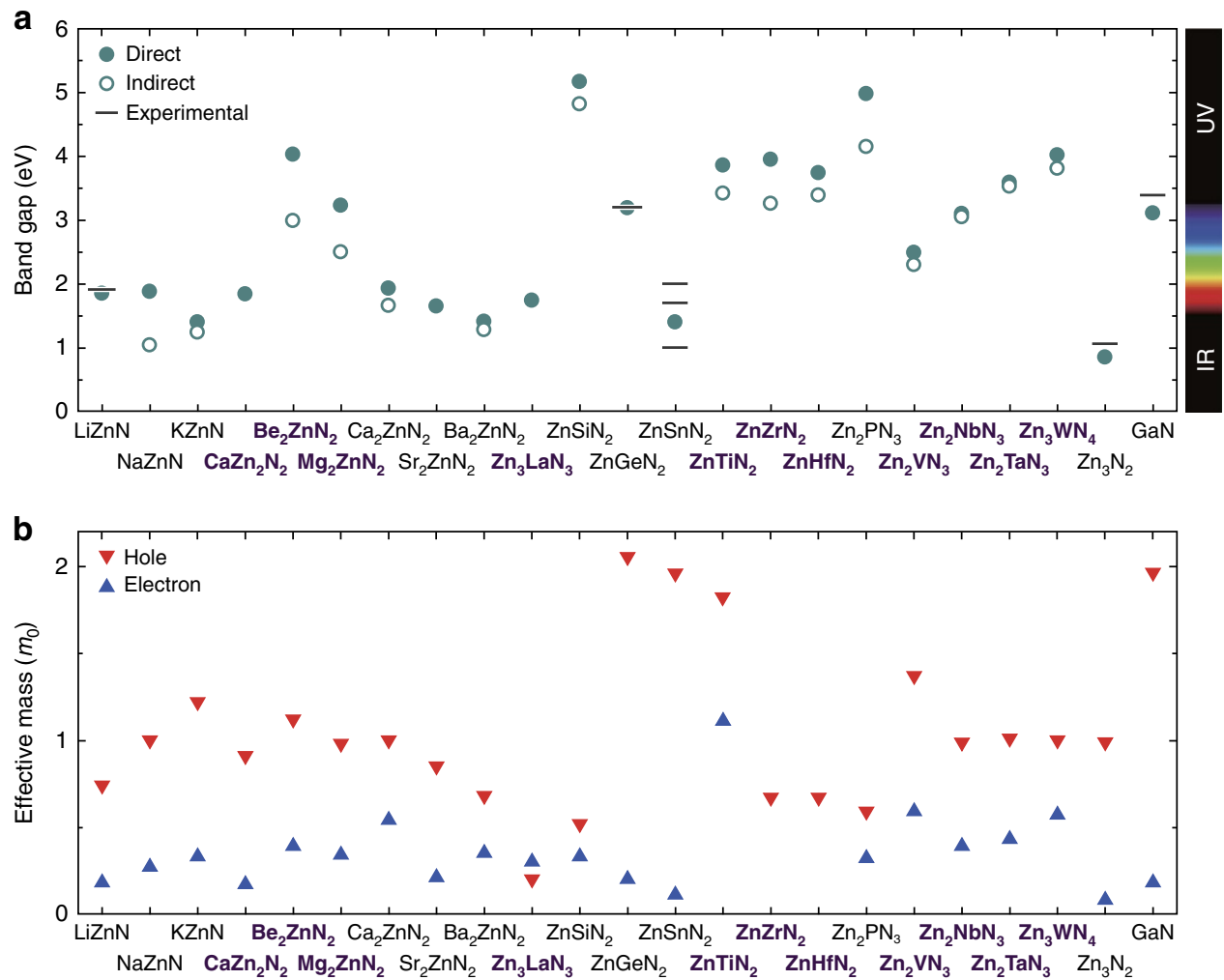

Figure 1 | Electronic properties of theoretically identified ternary zinc nitrides. (a) Bandgaps. Filled and open circles denote the values for direct and indirect gaps, respectively. Available experimental values are shown with bars (see Supplementary Table 4 for tabulated values and references).

(b) Effective masses for holes and electrons normalized by the free-electron rest mass, $m_{0}$. The values for the directions that provide the smallest effective masses are shown (see Supplementary Table 5 for tabulated values). Heavy holes are considered when the valence band maximum is degenerate or nearly degenerate ( $<0.1 \mathrm{eV}$ differences in band energies). The values for $Z \mathrm{n}_{3} \mathrm{~N}_{2}$ and $\mathrm{GaN}$ are also shown as references. As-yet-unreported nitrides are indicated with a bold purple font.

their appealing band structures are unveiled in the present study. In addition, the majority of the identified nitrides consist solely of abundant elements.

Among the known nitrides, $\mathrm{ZnSiN}_{2}, \mathrm{ZnGeN}_{2}$ and $\mathrm{ZnSnN}_{2}$ are found to favour a wurtzite-derived crystal structure in consistency with previous experiments ${ }^{7,24}$. $\mathrm{ZnTiN}_{2}$ is predicted to take this crystal structure among the newly identified $\mathrm{Zn}-\mathrm{IV}-\mathrm{N}_{2}$ compounds, whereas $\mathrm{ZnZrN}_{2}$ and $\mathrm{ZnHfN}_{2}$ are energetically more favourable with an alternate, $P 3 m 1$ crystal structure obtained using the evolutionary algorithm. The present results extend the wurtzite derivatives from $\mathrm{Zn}-\mathrm{IV}-\mathrm{N}_{2}$ to those involving group $\mathrm{V}$ and VI elements. $\mathrm{Zn}_{2} \mathrm{PN}_{3}$ can be regarded as a prototype of such kind with a group $\mathrm{V}$ element. Our calculations suggest that $\mathrm{Zn}_{2} \mathrm{VN}_{3}, \mathrm{Zn}_{2} \mathrm{NbN}_{3}$ and $\mathrm{Zn}_{2} \mathrm{TaN}_{3}$ are stable in this $\mathrm{Zn}_{2} \mathrm{PN}_{3}$ structure. In addition, $\mathrm{Zn}_{3} \mathrm{WN}_{4}$ is predicted to take a wurtzite-derived structure as well. In total, 10 unique structure types are observed for the 21 identified nitrides (Supplementary Table 3; Supplementary Fig. 1).

The hole and electron effective masses of many of the identified nitrides are comparable to or even smaller than those of $\mathrm{Zn}_{3} \mathrm{~N}_{2}$ and $\mathrm{GaN}$. In particular, much smaller hole effective masses than that of GaN $\left(2.0 m_{0}\right)$ are recognized for a number of ternary zinc nitrides. This is partly attributed to the hybridization of the $\mathrm{Zn}-3 d$ orbitals near the VBM and is appealing in view of potential applications utilizing $p$-type conductivity. Especially, $\mathrm{Zn}_{3} \mathrm{LaN}_{3}$ shows a non-degenerate VBM with an exceedingly small hole effective mass of $0.2 m_{0}$ (Fig. 1b; Supplementary Fig. 4). Moreover, some of the identified nitrides have direct bandgaps that are advantageous for light emission and harvesting. Indirect-gap compounds with slightly larger direct gaps can also be good candidates for photoabsorbers in solar cells ${ }^{13,15}$. Identified nitrides having such indirect or direct band structures and exhibiting good matching with the solar spectrum (bandgaps of $\sim 0.8$ to $\sim 1.9 \mathrm{eV}$ ) include LiZnN, $\mathrm{KZnN}, \mathrm{CaZn}_{2} \mathrm{~N}_{2}, \mathrm{Sr}_{2} \mathrm{ZnN}_{2}$, $\mathrm{Ba}_{2} \mathrm{ZnN}_{2}, \mathrm{Zn}_{3} \mathrm{LaN}_{3}$ and $\mathrm{ZnSnN}_{2}$ (Fig. 1a). In particular, the present study reveals the properties of $\mathrm{Ba}_{2} \mathrm{ZnN}_{2}$ with a theoretical indirect gap of $1.3 \mathrm{eV}$ and a high absorption coefficient of $5 \times 10^{4} \mathrm{~cm}^{-1}$ near the absorption threshold at $1.5 \mathrm{eV}$, which are suited for thin-film photovoltaics (Supplementary Fig. 5). Compounds with rather wide gaps $(>4 \mathrm{eV})$ together with small effective masses are of interest for potential applications in power electronics, where wider gaps allow for higher breakdown voltages. Promising systems in this respect are $\mathrm{ZnSiN}_{2}$ and $\mathrm{Zn}_{2} \mathrm{PN}_{3}$.

Among the identified nitrides, $\mathrm{Ca}_{2} \mathrm{ZnN}_{2}$ and $\mathrm{CaZn}_{2} \mathrm{~N}_{2}$ are especially attractive due to their earth-abundant constituents, and small hole and electron effective masses. The synthesis of $\mathrm{Ca}_{2} \mathrm{ZnN}_{2}$ has been reported ${ }^{27}$, but the electronic properties have not thus far been established experimentally. Electronic density of states from a first-principles calculation has been reported in ref. 30 and our result shown in Fig. $2 \mathrm{c}$ is similar in the shape of the valence and conduction bands. $\mathrm{Ca}_{2} \mathrm{ZnN}_{2}$ is predicted to have an indirect-type band structure with a minimum bandgap of $1.7 \mathrm{eV}$ (Figs 1a and 2b, left of panel). Ca-3d states mainly constitute electronic states near the conduction band minimum (CBM) (Fig. 2c, left of panel); nevertheless, the electron effective mass is as small as $0.5 m_{0}$ for a particular direction $(\Sigma-\Gamma)$, and a small hole effective mass of $1.0 m_{0}$ is also appealing (Fig. 1b). The optical absorption spectrum shows a threshold of $\sim 2.0 \mathrm{eV}$, which is $\sim 0.3 \mathrm{eV}$ above the indirect-gap (Fig. 2d, left of panel). 
a

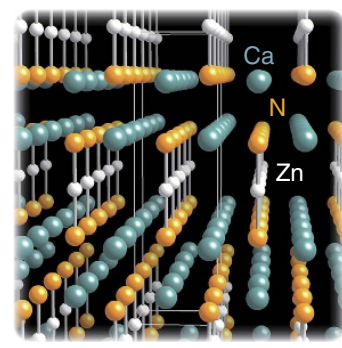

$\mathrm{Ca}_{2} \mathrm{ZnN}_{2}$

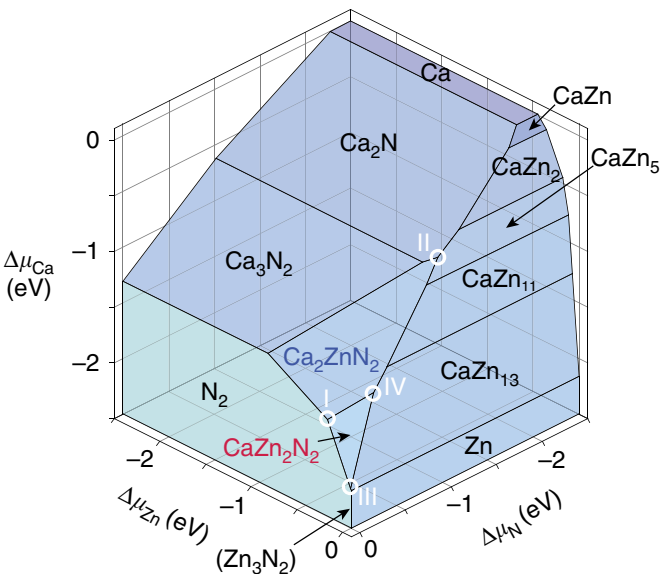

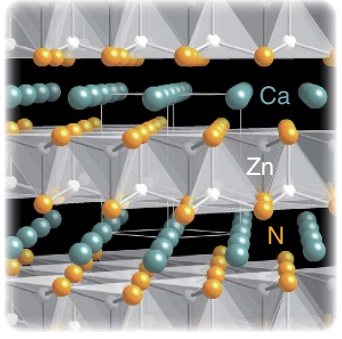

$\mathrm{CaZn} \mathrm{N}_{2}$ b

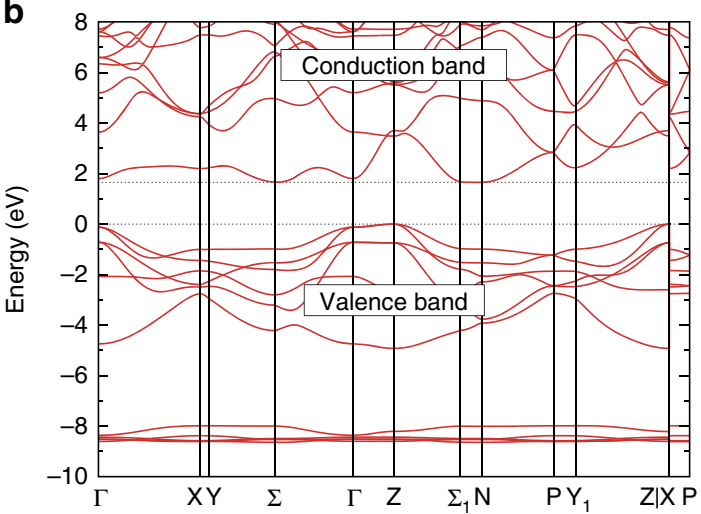

C

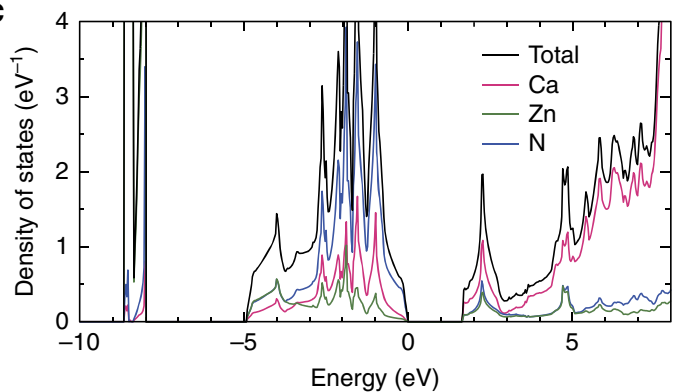

d

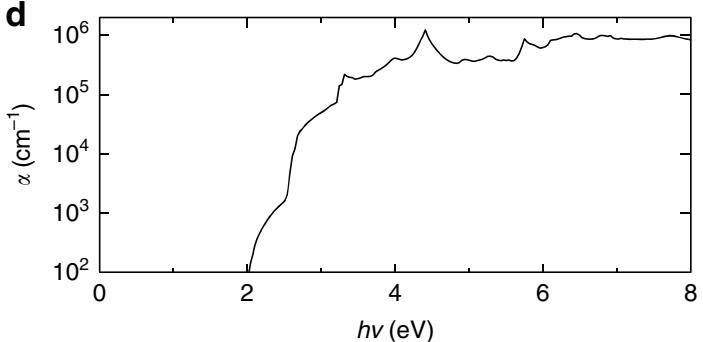

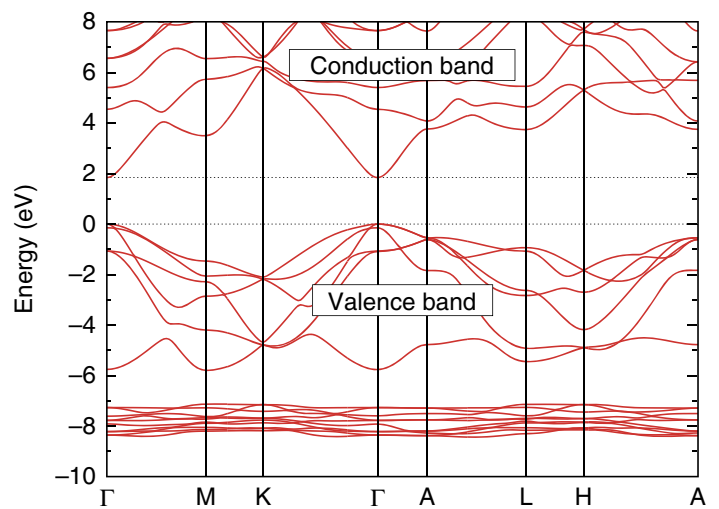
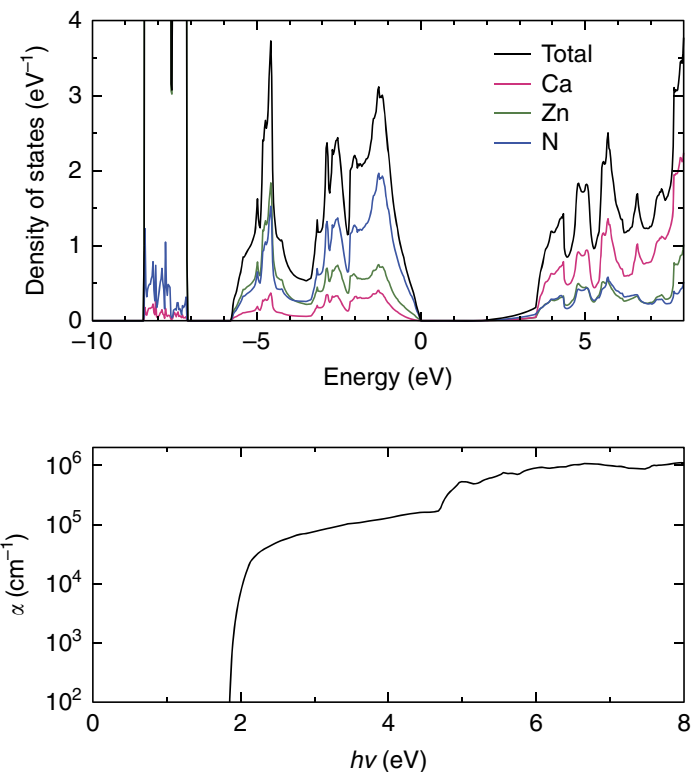

Figure 2 | Theoretically predicted characteristics of $\mathbf{C a}_{\mathbf{2}} \mathbf{Z n N} \mathbf{N}_{\mathbf{2}}$ and $\mathbf{C a Z n} \mathbf{2} \mathbf{N}_{\mathbf{2}}$. (a) Ca-Zn-N ternary phase diagram at OK and O GPa, showing the stable region of $\mathrm{Ca}_{2} \mathrm{ZnN}_{2}$ and $\mathrm{CaZn} \mathrm{N}_{2}$ in the chemical potential space. The chemical potentials $\Delta \mu_{i}(i=\mathrm{Ca}, \mathrm{Zn}$ and $\mathrm{N})$ are relative to those at the standard states, which are taken to be the $\mathrm{Ca}$ and $\mathrm{Zn}$ metals, and the $\mathrm{N}_{2}$ molecule. The $\mathrm{Zn}_{3} \mathrm{~N}_{2}$ phase is metastable and indicated in parenthesis. Chemical potential conditions I-IV are considered in the discussion of point-defect energetics. On the left and right sides of panel are the crystal structures of $\mathrm{Ca}_{2} \mathrm{ZnN} \mathrm{N}_{2}$ and $\mathrm{CaZn}_{2} \mathrm{~N}_{2}$, respectively. The frames represent the conventional unit cells ( $14 / \mathrm{mmm}$ (tetragonal) and $P \overline{3} \mathrm{~m} 1$ (trigonal), respectively). The Ca atoms (green) and $\mathrm{Zn}$ atoms (white) are coordinated by five and two $\mathrm{N}$ atoms (yellow), respectively, in $\mathrm{Ca}_{2} \mathrm{ZnN}_{2}$, whereas by six and four $\mathrm{N}$ atoms in $\mathrm{CaZn} \mathrm{n}_{2} \mathrm{~N}_{2}$; only $\mathrm{Zn}-\mathrm{N}$ bonds are illustrated for easy visualization. (b) Electronic band structures. (c) Total and site-projected electronic densities of states per formula unit. (d) Absorption spectra ( $\alpha$ : absorption coefficient; $h v$ : photon energy). For b-d, the left and right sides of each panel show results for $\mathrm{Ca}_{2} \mathrm{ZnN} \mathrm{N}_{2}$ and $\mathrm{CaZn} \mathrm{n}_{2} \mathrm{~N}_{2}$, respectively. 
The other ternary phase, $\mathrm{CaZn}_{2} \mathrm{~N}_{2}$, has not been reported previously to the best of our knowledge. Our calculations predict that this phase is stable against the known competing elementary, binary and ternary phases, including $\mathrm{Ca}_{2} \mathrm{ZnN}_{2}$ (Fig. 2a). It takes a relatively simple trigonal structure, where the $\mathrm{Ca}$ and $\mathrm{Zn}$ atoms are coordinated by six and four $\mathrm{N}$ atoms, respectively (Fig. 2a). The highest valence states have an $\mathrm{N}-2 p$ characteristic with sizable contributions of $\mathrm{Zn}$ and $\mathrm{Ca}$ orbitals (Fig. 2c, right of panel). The cation $s$ orbitals mainly constitute electronic states near the CBM in stark contrast to the case of $\mathrm{Ca}_{2} \mathrm{ZnN}_{2}$. These bands show large dispersions (Fig. 2b, right of panel) and thereby yield small effective masses of $0.9 m_{0}$ and $0.2 m_{0}$ for heavy holes and electrons, respectively (Fig. 1b); the heavy hole effective mass is about half the value of $\mathrm{GaN}$ and the electron effective mass is comparable to that of GaN. The symmetrically allowed electronic transitions over the direct gap lead to a steep optical absorption threshold and slightly above that, the absorption coefficient reaches as high as $5 \times 10^{4} \mathrm{~cm}^{-1}$ (Fig. $2 \mathrm{~d}$, right of panel). The direct bandgap of $1.8 \mathrm{eV}$ (Figs $1 \mathrm{a}$ and $2 \mathrm{~b}$, right of panel) corresponds to a red region in visible light when light emission is considered. It would also be suitable as a solar cell photoabsorber, given the theoretical photovoltaic energy conversion efficiency at the Shockley-Queisser limit is $27 \%$ for this bandgap under the air mass $1.5 \mathrm{G}$ sunlight ${ }^{31}$. The bandgap can be narrowed via alloying towards a higher theoretical efficiency, as discussed later.

Experimental verification of $\mathrm{Ca}_{2} \mathrm{ZnN}_{2}$ and $\mathrm{CaZn}_{2} \mathrm{~N}_{2}$. The theoretical phase diagram of the $\mathrm{Ca}-\mathrm{Zn}-\mathrm{N}$ ternary system indicates that the stable region of the newly identified $\mathrm{CaZn}_{2} \mathrm{~N}_{2}$ phase is limited to high nitrogen chemical potential conditions. The corresponding nitrogen partial pressure is much higher than $0.1 \mathrm{MPa}$ at, for instance, $800 \mathrm{~K}$ and above (Fig. 2a; Supplementary Figs 6 and 7; Supplementary Note 1). Therefore, we have utilized high-pressure synthesis that can allow access to such conditions. Conventional synthesis without applying external pressure successfully forms the previously reported $\mathrm{Ca}_{2} \mathrm{ZnN}_{2}$ (Fig. 3a) and predominantly yields this phase even with the starting composition corresponding to $\mathrm{CaZn}_{2} \mathrm{~N}_{2}$ (Supplementary Fig. 8). Using high pressure, trigonal $\mathrm{CaZn}_{2} \mathrm{~N}_{2}$ is obtained as the primary component with a minority presence of $\mathrm{Zn}$ metal (Fig. 3b; Supplementary Fig. 9; Supplementary Tables 6 and 7); the origin of $\mathrm{Zn}$ metal segregation is a chemical reaction between the Ca component and $\mathrm{BN}$ in the high-pressure cell. This result demonstrates that high-pressure synthesis is effective to realize complex nitrides that are stable only under high nitrogen partial pressure conditions. The experimentally determined lattice parameters of $\mathrm{CaZn}_{2} \mathrm{~N}_{2}$ are $a=3.46380(11) \AA$ and $c=6.00969(30) \AA$. These values are close to theoretically predicted lattice parameters of $a=3.454 \AA$ and $c=5.990 \AA$, with $0.3 \%$ differences between experiment and theory for both $a$ and $c$. The $\mathrm{Ca}$ to $\mathrm{Zn}$ ratio measured for a $\mathrm{CaZn}_{2} \mathrm{~N}_{2}$ region using the electron probe micro-analyzer is $1.00(1): 1.97(3)$, which is almost exactly the target composition.

As mentioned above, our calculations predict that the previously reported $\mathrm{Ca}_{2} \mathrm{ZnN}_{2}$ is an indirect-type semiconductor, whereas the newly identified $\mathrm{CaZn}_{2} \mathrm{~N}_{2}$ is direct-type. Corresponding to such differences in theoretical band structures and absorption spectra between the two phases (Fig. 2b,d), $\mathrm{CaZn}_{2} \mathrm{~N}_{2}$ exhibits a steeper absorption threshold, with an energy of $\sim 1.9 \mathrm{eV}$ at $300 \mathrm{~K}$ (Fig. 3c). Furthermore, red photoluminescence originating from a band-to-band transition is observed (Fig. 3d). The band-edge luminescence peak is located at $1.98 \mathrm{eV}$ at $10 \mathrm{~K}$ and gradually shifts to lower energies with increasing temperature, down to $1.92 \mathrm{eV}$ at $300 \mathrm{~K}$. It should be noted that the red luminescence is visible even at room temperature (Supplementary Fig. 10) and no deep-level emissions are observed despite the polycrystalline nature. Therefore, this nitride is a promising candidate not only for a photoabsorber, but also a red light emitter. The diffuse reflectance and photoluminescence results indicate that the direct bandgap of $\mathrm{CaZn}_{2} \mathrm{~N}_{2}$ is $\sim 1.9 \mathrm{eV}$ at room temperature. This value is close to the theoretically predicted direct gap of $1.83 \mathrm{eV}$. The bandgap of the $\mathrm{Ca}_{2} \mathrm{ZnN}_{2}$ phase has not been reported either, and we estimate its indirect and direct gaps to be $\sim 1.6$ and $\sim 1.9 \mathrm{eV}$ from the diffuse reflectance, respectively, again in good agreement with the corresponding theoretical values of 1.65 and $1.92 \mathrm{eV}$. The theoretically proposed earth-abundant nitride, $\mathrm{CaZn}_{2} \mathrm{~N}_{2}$, is thus verified experimentally, as well as $\mathrm{Ca}_{2} \mathrm{ZnN}_{2}$ whose fundamental properties have not been well established previously.

Predictions on the bandgap engineering of $\mathrm{CaZn}_{2} \mathrm{~N}_{2}$. The applications of semiconductors often require tuning of bandgaps, typically via alloying. This is explored for $\mathrm{CaZn}{ }_{2} \mathrm{~N}_{2}$ theoretically. $\mathrm{CaMg}_{2} \mathrm{~N}_{2}$ (ref. 32), which is a known phase isostructural to $\mathrm{CaZn}_{2} \mathrm{~N}_{2}$, is found to be a good alloying agent (Fig. 4a). As expected from a relatively small lattice mismatch $(+2.1$ and $+1.0 \%$ against $\mathrm{CaZn}_{2} \mathrm{~N}_{2}$ for lattice parameters $a$ and $c$, respectively), our cluster expansion and grand canonical Monte Carlo simulations predict alloy formation for the whole composition range of $\mathrm{CaMg}_{2 x} \mathrm{Zn}_{2(1-x)} \mathrm{N}_{2}(0 \leq x \leq 1)$ even at room temperature (Supplementary Fig. 11). The bandgap of the $\mathrm{CaMg}_{2 x} \mathrm{Zn}_{2(1-x)} \mathrm{N}_{2}$ alloy increases almost linearly with the $\mathrm{Mg}$ composition from $1.8 \mathrm{eV}$ to the bandgap of $\mathrm{CaMg}_{2} \mathrm{~N}_{2}, 3.3 \mathrm{eV}$, preserving the direct-type band structure (Fig. 4b). This covers most of the visible light range. The hole and electron effective masses of $\mathrm{CaMg}_{2} \mathrm{~N}_{2}$ are $1.8 m_{0}$ and $0.2 m_{0}$, respectively (Supplementary Table 5). These values, coupled with the similarity in valence and conduction band structures between $\mathrm{CaZn}_{2} \mathrm{~N}_{2}$ and $\mathrm{CaMg}_{2} \mathrm{~N}_{2}$ (Fig. 2b, right of panel; Supplementary Fig. 4v), imply that the electron effective mass does not change significantly by alloying, whereas the hole effective mass increases up to $1.8 m_{0}$. We note that this value is still comparable to the hole effective mass of $\mathrm{GaN}\left(2.0 m_{0}\right)$.

The bandgap of $\mathrm{CaZn}_{2} \mathrm{~N}_{2}$ can also be narrowed towards the near-infrared range. Isostructural $\mathrm{SrZn}_{2} \mathrm{~N}_{2}$, which is previously unreported and found to be metastable with respect to decomposition into competing phases (Supplementary Fig. 3f), shows a theoretical bandgap of $1.6 \mathrm{eV}$ (Fig. 4a) and the substitution of $\mathrm{Sr}$ for $\mathrm{Ca}$ reduces the bandgap of $\mathrm{CaZn}_{2} \mathrm{~N}_{2}$ (Fig. 4b). Given the similarity in band structures and carrier effective masses between $\mathrm{CaZn}_{2} \mathrm{~N}_{2}$ and $\mathrm{SrZn}_{2} \mathrm{~N}_{2}$ (Fig. 2b, right of panel; Supplementary Fig. 4x; Supplementary Table 5), the changes in the effective masses by alloying are expected to be small. The predicted mutual solubility of $C a Z n_{2} N_{2}$ and $\mathrm{SrZn}_{2} \mathrm{~N}_{2}$ is limited at low temperature, compared with the $\mathrm{CaZn}_{2} \mathrm{~N}_{2}-$ $\mathrm{CaMg}_{2} \mathrm{~N}_{2}$ system (Supplementary Fig. 12). Still, quenching from a moderate temperature $(\sim 1,000 \mathrm{~K}$ or above) or non-equilibrium growth would allow for bandgap tuning via alloying in a wide composition range. Isostructural $\mathrm{BaZn}_{2} \mathrm{~N}_{2}$ was also considered as an alloying agent, but is found to be unstable against lattice vibration (Supplementary Fig. 2y). Another option for bandgap narrowing is the substitution of $\mathrm{Cd}$ for $\mathrm{Zn}$. This is expected to reduce the bandgap of $\mathrm{CaZn}_{2} \mathrm{~N}_{2}$ substantially, given the theoretical bandgap of $0.4 \mathrm{eV}$ for $\mathrm{CaCd}_{2} \mathrm{~N}_{2}$; however, replacing too much $\mathrm{Zn}$ with $\mathrm{Cd}$ is likely to result in an excessive relaxation that leads to the breakdown of the $\mathrm{CaZn}_{2} \mathrm{~N}_{2}$ structure (Supplementary Method 2). In addition, the use of $\mathrm{Cd}$ would ideally be avoided in view of the toxicity of many of $\mathrm{Cd}$ 
a
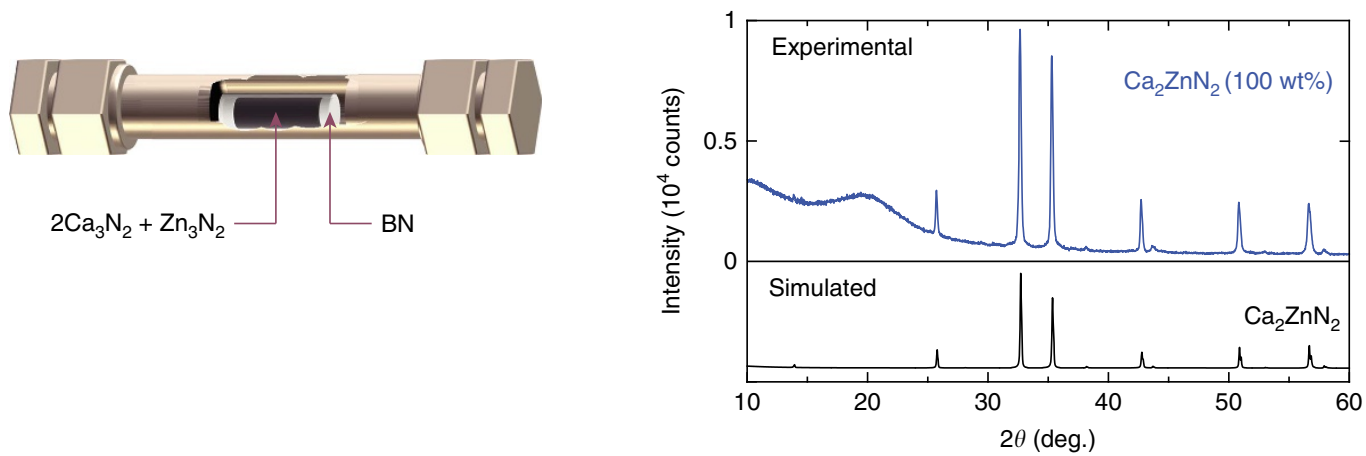

b
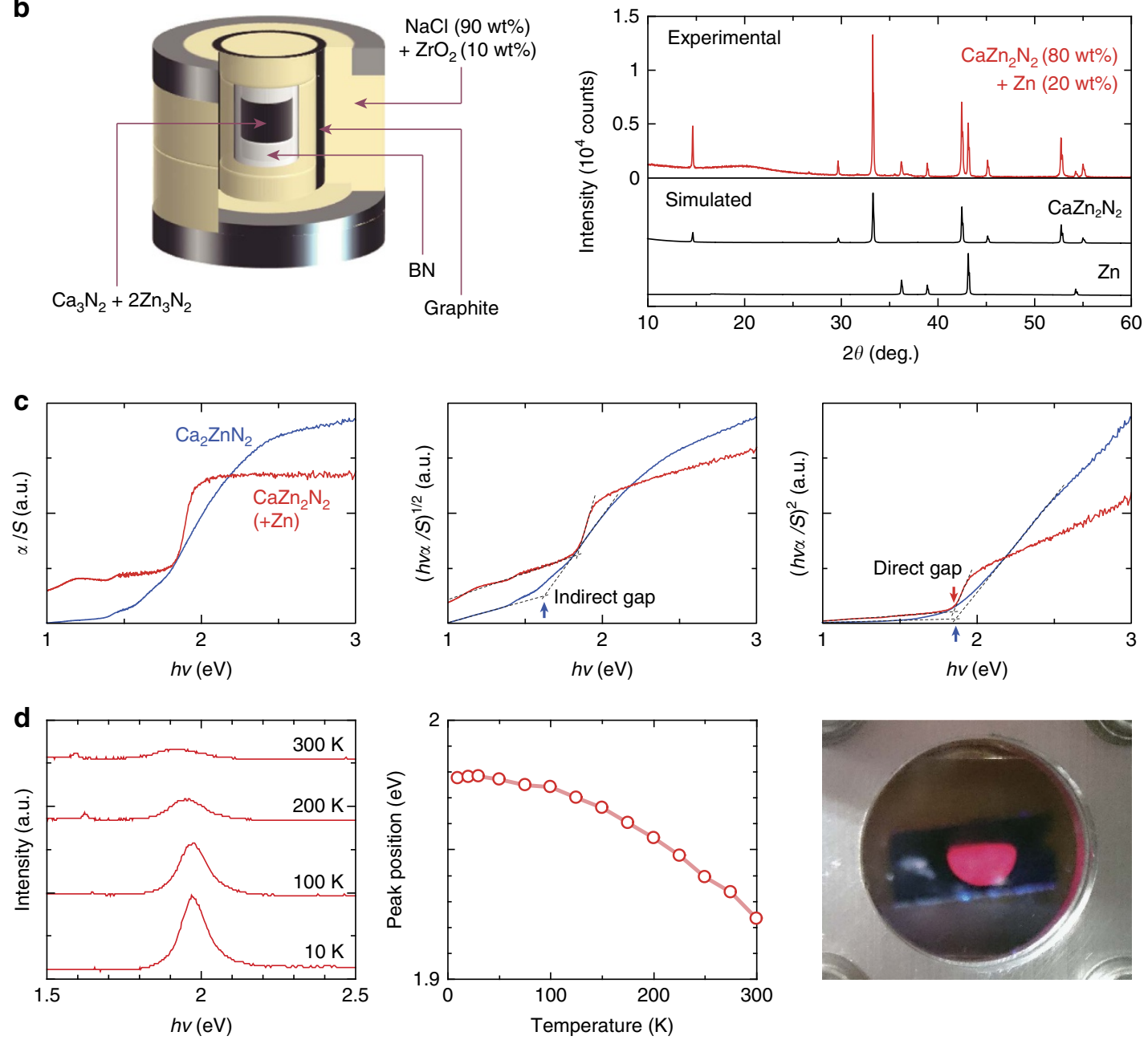

Figure 3 | Experimental verification of the $\mathbf{C a}_{\mathbf{2}} \mathbf{Z n N} \mathbf{N}_{\mathbf{2}}$ and $\mathbf{C a Z n} \mathbf{n}_{\mathbf{2}} \mathbf{N}_{\mathbf{2}}$ phases. Schematics of experimental set-ups and X-ray diffraction profiles for (a) a polycrystalline sample with a starting composition of $\mathrm{Ca}: \mathrm{Zn}: \mathrm{N}=2: 1: 2$ aiming at the formation of the $\mathrm{Ca}_{2} \mathrm{ZnN}_{2}$ phase, which was encapsulated in a sealed steel tube and annealed at $680^{\circ} \mathrm{C}$ for $40 \mathrm{~h}$, and (b) a polycrystalline sample treated at $1200^{\circ} \mathrm{C}$ and $5.0 \mathrm{GPa}$ for $1 \mathrm{~h}$ with a starting composition of 1:2:2 corresponding to $\mathrm{CaZn}_{2} \mathrm{~N}_{2}$. Also shown are simulated profiles that were obtained on the basis of the theoretically predicted crystal structure of $\mathrm{CaZn} \mathrm{N}_{2}$ and the reported crystal structures of $\mathrm{Ca}_{2} \mathrm{ZnN}_{2}$ and $\mathrm{Zn}$. The broad peaks around $2 \theta=20^{\circ}$ originate from sample capsules used in the measurements. (c) Absorption spectra of $\mathrm{Ca}_{2} \mathrm{ZnN}_{2}$ and $\mathrm{CaZn}_{2} \mathrm{~N}_{2}$ derived from diffuse reflectance spectra at $300 \mathrm{~K}$ and the Kubelka-Munk relation ( $\alpha$ : absorption coefficient; S: scattering factor; and $h v$ : photon energy). (d) Photoluminescence (PL) from CaZn $\mathrm{N}_{2}: \mathrm{PL}$ spectra at $10,100,200$ and $300 \mathrm{~K}$ (left of panel), the temperature dependence of the PL peak position (middle of panel) and a photograph of red PL at $10 \mathrm{~K}$ (right of panel).

compounds. The bandgap of $\mathrm{CaZn}_{2} \mathrm{~N}_{2}$ is thus most readily tuned via alloying with $\mathrm{CaMg}_{2} \mathrm{~N}_{2}$ towards higher energies. We note that the lattice mismatch in the $\mathrm{CaZn}_{2} \mathrm{~N}_{2}-\mathrm{CaMg}_{2} \mathrm{~N}_{2}$ system $(\sim 2 \%)$ is much smaller than that of the GaN-InN system $(\sim 10 \%)$, as shown in Fig. 4a. This, in turn, allows for the stable alloy formation as discussed above.
Predictions on the dopability of $\mathrm{Ca}_{2} \mathrm{ZnN}_{2}$ and $\mathrm{CaZn}_{2} \mathrm{~N}_{2}$. We now discuss the dopability of $\mathrm{Ca}_{2} \mathrm{ZnN}_{2}$ and $\mathrm{CaZn}_{2} \mathrm{~N}_{2}$ into $p$ and/or $n$ type, including the effect of alloying of $\mathrm{CaZn}_{2} \mathrm{~N}_{2}$ with $\mathrm{CaMg}_{2} \mathrm{~N}_{2}$, based on the defect chemistry, that is, whether carrier compensation by native defects can be sufficiently suppressed and whether dopants that act as shallow accepters or donors exist. The 

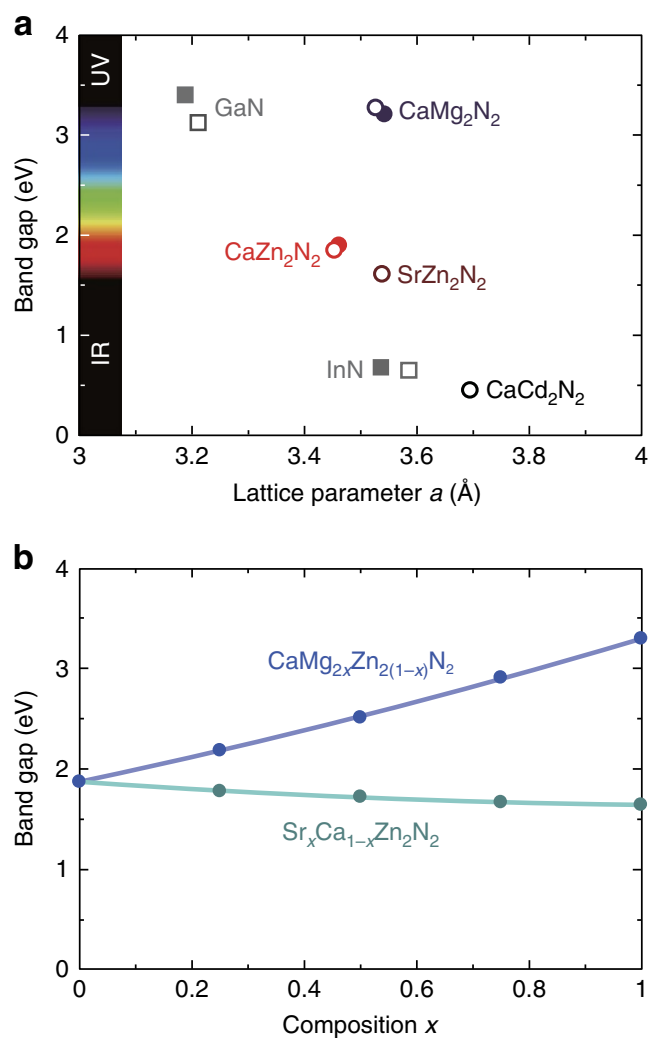

Figure 4 | Theoretical bandgaps of nitrides relevant to $\mathrm{CaZn}_{2} \mathrm{~N}_{2}$ and its alloys. (a) Bandgaps of $\mathrm{CaZn}_{2} \mathrm{~N}_{2}$ and relevant isostructural ternary nitrides versus lattice parameter $a$, alongside those of $\mathrm{GaN}$ and $\operatorname{lnN}$. Theoretical and experimental values are shown with open and filled symbols, respectively; the experimental gap and lattice parameter of $\mathrm{CaZn} \mathrm{n}_{2} \mathrm{~N}_{2}$ are obtained in the present study, whereas the other experimental values are from literature (see Supplementary Tables 4 and 8 for tabulated values and references). (b) Theoretical bandgaps of $\mathrm{CaMg}_{2 x} \mathrm{Zn}_{2(1-x)} \mathrm{N}_{2}$ and $\mathrm{Sr}_{x} \mathrm{Ca}_{1-x} \mathrm{Zn}_{2} \mathrm{~N}_{2}(0 \leq x \leq 1)$ alloys. The curves are quadratic fittings to $E_{\mathrm{g}}=(1-x) E_{\mathrm{g}}^{\mathrm{A}}+x E_{\mathrm{g}}^{\mathrm{B}}-b x(1-x)$, where $E_{\mathrm{g}}, E_{\mathrm{g}}^{\mathrm{A}}$ and $E_{\mathrm{g}}^{\mathrm{B}}$ are the bandgaps of the alloy and alloy components $A$ and $B$, respectively. Band bowing parameters $b$ are 0.24 and $0.17 \mathrm{eV}$ for $\mathrm{CaMg}_{2 x} \mathrm{Zn}_{2(1-x)} \mathrm{N}_{2}$ and $\mathrm{Sr}_{x} \mathrm{Ca}_{1-x} \mathrm{Zn}_{2} \mathrm{~N}_{2}$, respectively.

theoretical defect energetics indicates that dominant donor-type native defects are $\mathrm{N}$ vacancies $\left(V_{\mathrm{N}}\right)$ in both $\mathrm{Ca}_{2} \mathrm{ZnN}_{2}$ and $\mathrm{CaZn}_{2} \mathrm{~N}_{2}$ (Fig. 5a,b). They form shallow donor levels, which are associated with host CBM states perturbed by the $\mathrm{N}$ vacancies. The formation energies of the $\mathrm{N}$ vacancies are relatively low under N-poor conditions, such as condition II for $\mathrm{Ca}_{2} \mathrm{ZnN}_{2}$ and IV for $\mathrm{CaZn}_{2} \mathrm{~N}_{2}$. In particular, the $\mathrm{N}$ vacancy shows quite low formation energy in $\mathrm{Ca}_{2} \mathrm{ZnN}_{2}$ even with the Fermi level near the CBM, implying its native $n$-type characteristic when prepared under N-poor conditions. Turning to N-rich conditions, as represented by condition I, allows for the suppression of the $\mathrm{N}$ vacancy formation. In connection with this relatively large chemical potential dependence, our $\mathrm{Ca}_{2} \mathrm{ZnN}_{2}$ sample exhibits a semiconducting behaviour with an activation energy of $\sim 20 \mathrm{meV}$ (Supplementary Fig. 15), whereas a previous study obtained an insulating sample ${ }^{2 P}$. Among acceptor-type defects, the $\mathrm{Ca}$ and $\mathrm{Zn}$ vacancies $\left(V_{\mathrm{Ca}}\right.$ and $\left.V_{\mathrm{Zn}}\right)$ are dominant in both nitrides. Interstitial defects $\left(\mathrm{Ca}_{i}, \mathrm{Zn}_{i}\right.$ and $\left.\mathrm{N}_{i}\right)$ generally show high formation energies. Cation antisites are often major defects in ternary compounds, while the formation energies of $\mathrm{Ca}-\mathrm{on}-\mathrm{Zn}$ and $\mathrm{Zn}$-on-Ca antisites $\left(\mathrm{Ca}_{\mathrm{Zn}}\right.$ and $\left.\mathrm{Zn}_{\mathrm{Ca}}\right)$ are not significantly low $(>1.2 \mathrm{eV})$ in both $\mathrm{Ca}_{2} \mathrm{ZnN}_{2}$ and $\mathrm{CaZn} \mathrm{N}_{2} \mathrm{~N}_{2}$. This is presumably because of a relatively large-size mismatch between $\mathrm{Ca}(\mathrm{II})$ and $\mathrm{Zn}(\mathrm{II})$ ions. More importantly, the isovalence of $\mathrm{Ca}$ and $\mathrm{Zn}$ results in neutral and, therefore, electrically inactive antisite defects. This leads to a design principle of ternary compound semiconductors: a large-size mismatch and/or the isovalence of two types of cations are desirable to suppress the charge compensation by antisite defects.

The controllable range of the Fermi level is restricted by the spontaneous formation of charged native defects that compensate carriers, that is, their negative formation energies ${ }^{33}$. All defects show positive formation energies in $\mathrm{Ca}_{2} \mathrm{ZnN}_{2}$ under $\mathrm{N}$-rich conditions as represented by condition I, irrespective of the Fermi level position. Similarly in $\mathrm{CaZn}_{2} \mathrm{~N}_{2}$, positive formation energies are recognized for almost whole range of the Fermi level under both N-rich (III) and N-poor (IV) conditions. Therefore, electron and hole densities are not significantly limited in terms of native defect compensation, when the Fermi level is controlled towards the VBM or CBM via doping. In other words, both $n$ - and $p$-type doping is feasible in both $\mathrm{Ca}_{2} \mathrm{ZnN}_{2}$ and $\mathrm{CaZn}_{2} \mathrm{~N}_{2}$. The defect energetics in $\mathrm{CaMg}_{2} \mathrm{~N}_{2}$ (Fig. 5c), in contrast, indicates that electron carrier density is limited by the compensation by cation vacancies in $\mathrm{CaMg}_{2 x} \mathrm{Zn}_{2(1-x)} \mathrm{N}_{2}$ alloys with a high $\mathrm{Mg}$ content.

The above assessment of the dopability assumes the availability of dopants that act as shallow acceptors or donors. Our calculations indeed found such dopants having small size mismatches with host ions: $\mathrm{Na}$ and $\mathrm{K}$ at the $\mathrm{Ca}$ site as shallow acceptors and $\mathrm{Ga}$ at the $\mathrm{Zn}$ site as a shallow donor in $\mathrm{Ca}_{2} \mathrm{ZnN}_{2}$, where $\mathrm{Al}$ at the $\mathrm{Zn}$ site acts as a deep donor; and $\mathrm{Na}$ and $\mathrm{K}$ at the $\mathrm{Ca}$ site as shallow acceptors, and $\mathrm{Al}$ and $\mathrm{Ga}$ at the $\mathrm{Zn}$ or $\mathrm{Mg}$ site as shallow donors in $\mathrm{CaZn}_{2} \mathrm{~N}_{2}$ and $\mathrm{CaMg}_{2} \mathrm{~N}_{2}$. Another assumption made is a thermodynamic equilibrium. The use of non-equilibrium growth and/or doping conditions can allow for the Fermi level control over the aforementioned limits.

\section{Discussion}

Our high-throughput first-principles screening has identified 10 previously reported and 11 unreported nitrides as promising semiconductors. The latter class of materials includes $\mathrm{CaZn}_{2} \mathrm{~N}_{2}$, which has a tunable direct bandgap and small effective masses, is comprised of only abundant elements, and is obtainable via high-pressure synthesis. Other predicted rare-element-free nitrides include newly identified $\mathrm{Mg}_{2} \mathrm{ZnN}_{2}, \mathrm{ZnTiN}_{2}$ and $\mathrm{ZnZrN}_{2}$, as well as $\mathrm{Ca}_{2} \mathrm{ZnN}_{2}, \mathrm{Sr}_{2} \mathrm{ZnN}_{2}, \mathrm{Ba}_{2} \mathrm{ZnN}_{2}$ and $\mathrm{Zn}_{2} \mathrm{PN}_{3}$, for which synthesis has been reported previously, but the applications as semiconductors have not been suggested to the best of our knowledge. The variety in bandgaps of the identified nitrides, coupled with small effective masses, widens the choice of nitride semiconductors that can be used in electronics, optoelectronics and photovoltaics. The present study demonstrates accelerated materials discovery via computational screening followed by targeted experiments, particularly showing high-pressure synthesis to be effective in the realization of as-yet-unreported nitrides.

\section{Methods}

Calculations of fundamental properties and stability. The first-principles calculations were conducted using the projector augmented-wave method $^{34}$ and either the Perdew-Burke-Ernzerhof generalized gradient approximation (PBE-GGA) functional ${ }^{35}$ or the Heyd-Scuseria-Ernzerhof (HSE06) hybrid functional ${ }^{36,37}$, as implemented in the Vienna $\mathrm{Ab}$ initio Simulation Package $(\text { VASP) })^{38,39}$. The PBE-GGA was used for screening in terms of thermodynamic and lattice dynamic stability. The HSE06 hybrid functional was employed for evaluating the bandgaps, carrier effective masses, electronic band structures, electronic densities of states, absorption spectra and point-defect energetics of the identified compounds. Thermodynamic stability was also investigated using HSE06 and such results for the $\mathrm{Ca}-\mathrm{Zn}-\mathrm{N}$ and $\mathrm{Ca}-\mathrm{Mg}-\mathrm{N}$ ternary systems are shown in Fig. 2a and Supplementary Fig. 13 for consistency with point-defect calculations. The phase diagrams were drawn using the CHESTA code ${ }^{40}$, where competing 
N-rich condition

a
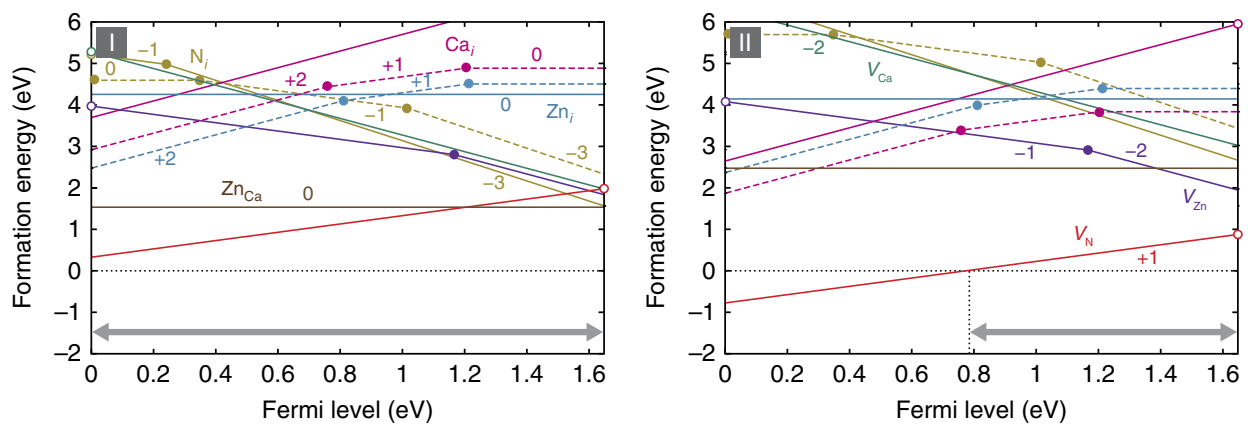

b $\mathrm{CaZn} \mathrm{N}_{2}$
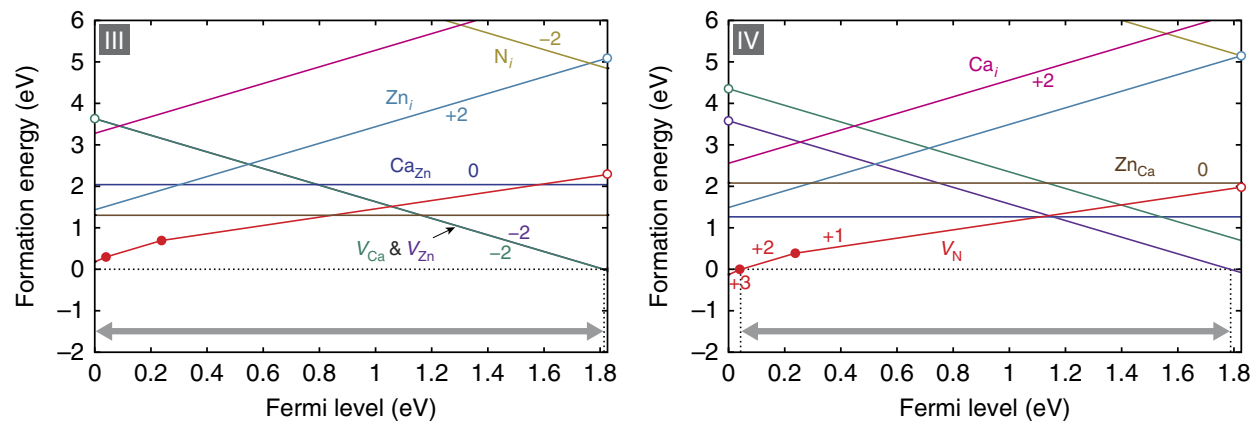

C

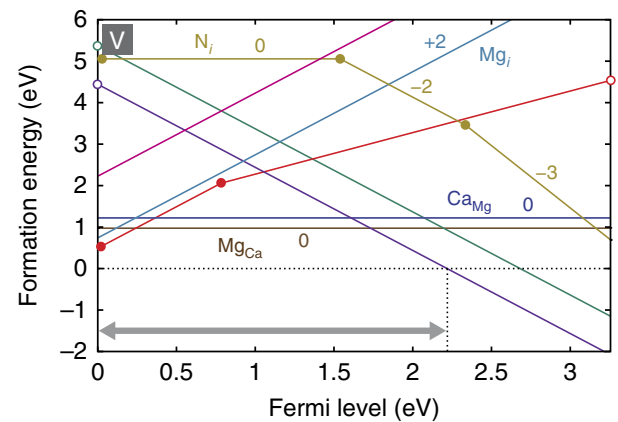

Figure 5 | Theoretical defect energetics in $\mathbf{C a}_{\mathbf{2}} \mathbf{Z n N} \mathbf{N}_{\mathbf{2}}, \mathbf{C a Z n} \mathbf{n}_{\mathbf{2}}$ and $\mathbf{C a M g} \mathbf{M}_{\mathbf{2}} \mathbf{N}_{\mathbf{2}}$. The formation energies of native point defects as a function of the Fermi level for (a) $\mathrm{Ca}_{2} \mathrm{ZnN}_{2}$ (b) $\mathrm{CaZn}_{2} \mathrm{~N}_{2}$ and (c) $\mathrm{CaMg}_{2} \mathrm{~N}_{2}$ under $\mathrm{N}$-rich and $\mathrm{N}$-poor chemical potential conditions, corresponding to I-VI indicated in Fig. 2a and Supplementary Fig. 13. The range of the Fermi level is given by the valence band maximum, which is set to zero, and the conduction band minimum. $V$ in defect species denotes vacancies. The subscripts designate defect sites, where $i$ means interstitial sites. The results for two interstitial sites in $\mathrm{Ca}_{2} \mathrm{ZnN}_{2}$ are shown with solid and broken lines (Supplementary Fig. 14). The charge states of defects, which correspond to the gradients as defined by equation (1) in the Methods section, are described; only the most energetically favourable charge state at a given Fermi level is shown for each defect. Positive and negative charge states mean donor and acceptor behaviour of defects, respectively. The Fermi level at which the favourable charge state changes corresponds to the positions of donor or acceptor levels, which are designated by filled circles; shallow donor or acceptor levels associated with electronic states inheriting host orbital characteristics are designated by open circles. The controllable ranges of the Fermi level, in which carrier compensation by spontaneous formation of native defects is avoidable, are indicated by arrows.

phases that are reported to be stable in the Materials Project database ${ }^{41}$ are considered. Plane-wave cutoff energies of 550 and $400 \mathrm{eV}$ were used for the geometry optimization of perfect crystals and for the calculations of fundamental and defect properties, respectively. Even $k$-point meshes were used in geometry optimization, which were determined on the basis of the convergence of PBE-GGA total energies: the criterion of the total energy change was set at $<0.005 \mathrm{meV}$ per atom per the number of incremental $k$ points. For instance, this results in an $8 \times 8 \times 4$ mesh for the wurtzite GaN unit cell. Three times finer meshes were used in the calculations of electronic densities of states and absorption spectra. The bandgaps obtained using the HSE06 hybrid functional are generally close to available experimental values for relevant systems as shown in Supplementary Table 4, alongside comparison with theoretical values from the $G W$ approximation $^{42}$ to many-body perturbation theory (see also a discussion in Supplementary Note 2). Effective masses were estimated by quadratic fittings of the bands that constitute the VBM and CBM, using fine sampling of $k$ points around the VBM and CBM. The absorption spectra were obtained via the calculations of dielectric functions within the independent particle approximation, where excitonic effects and phonon-assisted absorption were not considered. Details of the screening procedure based on these calculations are described in Supplementary Method 1.

Crystal structure prediction. The crystal structure search was performed using an evolutionary algorithm as implemented in the USPEX code ${ }^{12,26}$, in conjunction with first-principles calculations using the PBE-GGA as described above. The chemical formula for each system was fixed, but allowed to vary in multiples of between 1 and 4 . The calculations were considered converged when no lower energy structure could be found after 20 generations; with each generation containing 20 individual structures.

Alloy property calculations. The phase diagrams of the $\mathrm{CaZn}_{2} \mathrm{~N}_{2}-\mathrm{CaMg}_{2} \mathrm{~N}_{2}$ and $\mathrm{CaZn}_{2} \mathrm{~N}_{2}-\mathrm{SrZn}_{2} \mathrm{~N}_{2}$ pseudobinary systems were constructed using the PBE-GGA and the cluster expansion technique ${ }^{43,44}$ in conjunction with grand canonical Monte Carlo simulations, using the CLUPAN code $^{45}$. Quasi-random structures ${ }^{46}$ were employed for predicting band bowing using the HSE06 hybrid functional. 
More details of the alloy property calculations are given in Supplementary Method 2 and Supplementary Figs 16-21.

Modelling of point defects. Native point defects and dopants in $\mathrm{Ca}_{2} \mathrm{ZnN}_{2}$, $\mathrm{CaZn}_{2} \mathrm{~N}_{2}$ and $\mathrm{CaMg}_{2} \mathrm{~N}_{2}$ were modelled using 90-atom supercells (Supplementary Fig. 14). Atomic positions were relaxed with the cell parameters fixed at the perfect crystal values. Spin polarization was considered for odd-numbered electron systems. Defect formation energies were evaluated as ${ }^{47}$

$$
E_{\mathrm{f}}=E_{\mathrm{d}}-E_{\mathrm{p}}-\sum \Delta n_{i} \mu_{i}+q \varepsilon_{\mathrm{F}},
$$

where $E_{\mathrm{d}}$ is the total energy of a supercell containing a defect in charge state $q, E_{\mathrm{p}}$ is that of the perfect crystal supercell and $\Delta n_{i}$ is the difference in the number of constituent atom $i$ between these supercells. $\mu_{i}$ and $\varepsilon_{\mathrm{F}}$ are the chemical potential of atom $i$ and the Fermi level, respectively. $E_{\mathrm{d}}$ and $E_{\mathrm{p}}$ are evaluated using the HSE06 hybrid functional. The finite-size effects of supercells associated with electrostatic interactions between charged defects, their periodic images and the charge compensating background were corrected using the scheme reported in refs 48,49 . Our implementation accounts for the anisotropic screening of defect charges using dielectric tensors. In addition, atomic-site local potential is used as a potential marker, which has been shown to be effective for relaxed atomic configurations ${ }^{49}$.

Synthesis of $\mathrm{Ca}_{\mathbf{2}} \mathbf{Z n N} \mathbf{N}_{\mathbf{2}}$ and $\mathbf{C a Z n} \mathbf{n}_{\mathbf{2}} \mathbf{N}_{\mathbf{2}}$. Polycrystalline $\mathrm{Ca}_{2} \mathrm{ZnN}_{2}$ and $\mathrm{CaZn} \mathrm{N}_{2}$ disks and powders were prepared by solid-state reactions. Two kinds of common precursor nitrides, $\mathrm{Ca}_{3} \mathrm{~N}_{2}$ and $\mathrm{Zn}_{3} \mathrm{~N}_{2}$, were employed in both cases. $\mathrm{Ca}_{3} \mathrm{~N}_{2}$ was synthesized by heating dendritic pieces of Ca metal (purity: 99.99\%, Sigma-Aldrich Co. LLC.) in an electric furnace, directly connected with a glove box filled with dry inert $\mathrm{Ar}$ gas (dew point less than $-90^{\circ} \mathrm{C}$, oxygen concentration $<1$ p.p.m.), at $900^{\circ} \mathrm{C}$ for $10 \mathrm{~h}$ under $\mathrm{N}_{2}$ gas (purity: $>99.9998$ vol\% (G2)) flow atmosphere. For $\mathrm{Zn}_{3} \mathrm{~N}_{2}$, a commercially available reagent powder (purity: $99 \%$, Alfa Aesar Co.) was employed.

To obtain high-purity $\mathrm{Ca}_{2} \mathrm{ZnN}_{2}$, the precursor powders were mixed in the glove box at the molar ratio of $\mathrm{Ca}_{3} \mathrm{~N}_{2}: \mathrm{Zn}_{3} \mathrm{~N}_{2}=2.0: 1.0$ and then the mixture was uniaxially pressed into a disk $(6 \mathrm{~mm}$ in diameter and ca. $10 \mathrm{~mm}$ in height), which was covered by a BN crucible and sealed in an Ar-filled stainless tube as shown in Fig. 3a. The BN crucible prevents chemical reaction between the pressed disk and the stainless tube. The stainless tube was heated at $680^{\circ} \mathrm{C}$ (temperature as used in ref. 27) for $40 \mathrm{~h}$. For the synthesis of $\mathrm{CaZn}_{2} \mathrm{~N}_{2}$, we employed a belt-type high-pressure apparatus developed by Fukunaga et al..$^{50}$. The precursor powders were mixed in the glove box at the molar ratio of $\mathrm{Ca}_{3} \mathrm{~N}_{2}: \mathrm{Zn}_{3} \mathrm{~N}_{2}=1.0: 2.0$. The mixture was set up in a high-pressure cell composed of $\mathrm{NaCl}\left(10 \mathrm{wt} \% \mathrm{ZrO}_{2}\right)$ and BN with a carbon heater as shown in Fig. 3b. Pressure was increased to $5.0 \mathrm{GPa}$ for ca. $20 \mathrm{~min}$ at room temperature. Temperature was then elevated to $1,200^{\circ} \mathrm{C}$ in $30 \mathrm{~min}$ and retained for $1 \mathrm{~h}$. After the high-pressure/temperature treatment, the high-pressure cell was water-cooled to room temperature and then returned to ambient pressure. We slightly polished the sample pellet by a file to obtain an unreacted and fresh bulk region of $\mathrm{CaZn}_{2} \mathrm{~N}_{2}$ because the top surface of the pellet chemically reacted with a $\mathrm{BN}$ surface. The final size of the pellet was $5.5 \mathrm{~mm}$ in diameter and ca. $3 \mathrm{~mm}$ in height.

$\mathrm{CaZn}_{2} \mathrm{~N}_{2}$ is air-stable: any decomposed and impurity phases are not observed by X-ray diffraction, when the sample is exposed at room temperature in air for 1 week. It is stable up to at least $300^{\circ} \mathrm{C}$ in air and $500^{\circ} \mathrm{C}$ in $\mathrm{Ar}$ atmosphere; oxidization occurs at $400^{\circ} \mathrm{C}$ in air, and $\mathrm{CaZn}_{2} \mathrm{~N}_{2}$ decomposes into $\mathrm{Ca}_{2} \mathrm{ZnN}_{2}$ at $600^{\circ} \mathrm{C}$ in $\mathrm{Ar}$ atmosphere. On the other hand, $\mathrm{Ca}_{2} \mathrm{ZnN}_{2}$ rapidly decomposes into some oxides and hydroxides, such as $\mathrm{ZnO}$ and $\mathrm{Ca}(\mathrm{OH})_{2}$ in air.

Characterization. Crystalline phases were determined by X-ray diffraction using a $\mathrm{CuK} \alpha_{1}+\mathrm{K}_{2}$ source radiated from a rotary anode $(45 \mathrm{kV} \times 360 \mathrm{~mA}$, to detect a small amount of impurity phases) and a $\theta$-coupled $2 \theta$ scan with Bragg-Brentano geometry. We used an Ar-filled O-ring-sealed sample holder in the X-ray diffraction measurements for exact assessment of formed crystalline phases. Lattice parameters were determined using the Pawley method. Structure refinement was performed using the Rietveld method. These analyses were made using TOPAS Version 4.2 (Karlsruhe, Germany: Bruker AXS). X-ray diffraction profile simulations were conducted using the RIETAN-FP $\operatorname{code}^{51}$. Chemical composition, that is, atomic ratio of $\mathrm{Ca}$ to $\mathrm{Zn}$, was evaluated with an electron probe micro-analyzer employing a wavelength-dispersive spectroscopy mode.

Diffuse reflectance $(R)$ spectra of the polycrystalline samples were measured in the visible-near-infrared wavelength region using a conventional spectrophotometer. To estimate the optical bandgaps, the observed diffuse reflectance spectra were converted by the Kubelka-Munk equation $(1-R)^{2} /(2 R)=\alpha / S$, where $\alpha$ and $S$ denote an absorption coefficient and a scattering factor, respectively. Photoluminescence spectra were measured using excitation by third harmonic generation of Nd:YAG pulsed laser (wavelength: $355 \mathrm{~nm}$ ) with an energy density of $\sim 7 \mathrm{~mJ} \mathrm{~cm}^{-2}$.

Data availability. The authors declare that the data supporting the findings of this study are available within the article and its Supplementary Information file.

\section{References}

1. Ponce, F. A. \& Bour, D. P. Nitride-based semiconductors for blue and green light-emitting devices. Nature 386, 351-359 (1997).

2. Nomura, K. et al. Room-temperature fabrication of transparent flexible thin-film transistors using amorphous oxide semiconductors. Nature 432, 488-492 (2004).

3. Fujishima, A. \& Honda, K. Electrochemical photolysis of water at a semiconductor electrode. Nature 238, 37-38 (1972).

4. Hisatomi, T., Kubota, J. \& Domen, K. Recent advances in semiconductors for photocatalytic and photoelectrochemical water splitting. Chem. Soc. Rev. 43, 7520-7535 (2014).

5. Zerr, A. et al. Synthesis of cubic silicon nitride. Nature 400, 340-342 (1999)

6. Zerr, A., Miehe, G. \& Riedel, R. Synthesis of cubic zirconium and hafnium nitride having $\mathrm{Th}_{3} \mathrm{P}_{4}$ structure. Nat. Mater. 2, 185-189 (2003).

7. Lahourcade, L. et al. Structural and optoelectronic characterization of RF sputtered $\mathrm{ZnSnN}_{2}$. Adv. Mater. 25, 2562-2566 (2013).

8. Zakutayev, A. et al. Experimental synthesis and properties of metastable $\mathrm{CuNbN}_{2}$ and theoretical extension to other ternary copper nitrides. Chem. Mater. 26, 4970-4977 (2014).

9. Sarmiento-Pérez, R., Cerqueira, T. F. T., Körbel, S., Botti, S. \& Marques, M. A L. Prediction of stable nitride perovskites. Chem. Mater. 27, 5957-5963 (2015)

10. Curtarolo, S. et al. The high-throughput highway to computational materials design. Nat. Mater. 12, 191-201 (2013).

11. Woodley, S. M. \& Catlow, R. Crystal structure prediction from first principles. Nat. Mater. 7, 937-946 (2008).

12. Oganov, A. R., Lyakhov, A. O. \& Valle, M. How evolutionary crystal structure prediction works-and why. Acc. Chem. Res. 44, 227-237 (2011).

13. Yu, L. \& Zunger, A. Identification of potential photovoltaic absorbers based on first-principles spectroscopic screening of materials. Phys. Rev. Lett. 108, 068701 (2012)

14. Castelli, I. E. et al. Computational screening of perovskite metal oxides for optimal solar light capture. Energy Environ. Sci. 5, 5814-5819 (2012).

15. Zhang, X., Yu, L., Zakutayev, A. \& Zunger, A. Sorting stable versus unstable hypothetical compounds: The case of multi-functional ABX Half-Heusler filled tetrahedral structures. Adv. Funct. Mater. 22, 1425-1435 (2012).

16. Hautier, G., Miglio, A., Ceder, G., Rignanese, G.-M. \& Gonze, X. Identification and design principles of low hole effective mass p-type transparent conducting oxides. Nat. Commun. 4, 2292 (2013).

17. Zakutayev, A. et al. Theoretical prediction and experimental realization of new stable inorganic materials using the inverse design approach. J. Am. Chem. Soc. 135, 10048-10054 (2013).

18. Wu, Y., Lazic, P., Hautier, G., Persson, K. \& Ceder, G. First principles high throughput screening of oxynitrides for water-splitting photocatalysts. Energy Environ. Sci. 6, 157-168 (2013).

19. Castelli, I. E. et al. New light-harvesting materials using accurate and efficient bandgap calculations. Adv. Energy Mater. 5, 10.1002/aenm.201400915 (2015).

20. Gautier, R. et al. Prediction and accelerated laboratory discovery of previously unknown 18-electron ABX compounds. Nat. Chem. 7, 308-316 (2015).

21. Yoo, S.-H., Walsh, A., Scanlon, D. O. \& Soon, A. Electronic structure and band alignment of zinc nitride, $\mathrm{Zn}_{3} \mathrm{~N}_{2}$. RSC Adv. 4, 3306-3311 (2014).

22. Wriedt, H. A. The N-Zn (nitrogen-zinc) system. Bull. Alloy Phase Diag. 9, 247-251 (1988)

23. Kuriyama, K., Kato, T. \& Tanaka, T. Optical band gap of the filled tetrahedral semiconductor LiZnN. Phys. Rev. B 49, 4511-4513 (1994).

24. Endo, T., Sato, Y., Takizawa, H. \& Shimada, M. High-pressure synthesis of new compounds, $\mathrm{ZnSiN}_{2}$ and $\mathrm{ZnGeN}_{2}$ with distorted wurtzite structure. J. Mater. Sci. Lett. 11, 424-426 (1992).

25. Belsky, A., Hellenbrandt, M., Karen, V. L. \& Luksch, P. New developments in the ICSD: accessibility in support of materials research and design. Acta Crystallogr. Sect. B 58, 364-369 (2002)

26. Oganov, A. R. \& Glass, C. W. Crystal structure prediction using $a b$ initio evolutionary techniques: Principles and applications. J. Chem. Phys. 124, 244704 (2006).

27. Chern, M. Y. \& DiSalvo, F. J. Synthesis, structure, and properties of $\mathrm{Ca}_{2} \mathrm{ZnN}_{2}$ J. Solid State Chem. 88, 528-533 (1990).

28. Yamane, H. \& DiSalvo, F. J. Synthesis and crystal structure of $\mathrm{Sr}_{2} \mathrm{ZnN}_{2}$ and $\mathrm{Ba}_{2} \mathrm{ZnN}_{2}$. J. Solid State Chem. 119, 375-379 (1995).

29. Sedlmaier, Stefan J., Eberspächer, M. \& Schnick, W. High-pressure synthesis, crystal structure, and characterization of $\mathrm{Zn}_{2} \mathrm{PN}_{3}-\mathrm{A}$ new catenapolynitridophosphate. Z. Anorg. Allg. Chem. 637, 362-367 (2011).

30. Matar, S. F., Etourneau, J. \& Ouaini, N. Crystal and chemical anisotropy effects in $A E_{2} \mathrm{ZnN}_{2},(A E=\mathrm{Ca}, \mathrm{Sr}, \mathrm{Ba})$ from ab initio. Solid State Sci. 39, 10-14 (2015).

31. Shockley, W. \& Queisser, H. J. Detailed balance limit of efficiency of $p-n$ junction solar cells. J. Appl. Phys. 32, 510-519 (1961)

32. Schultz-Coulon, V. \& Schnick, W. $\mathrm{CaMg}_{2} \mathrm{~N}_{2}$ - a mixed alkaline-earth meta nitride with anti- $\mathrm{La}_{2} \mathrm{O}_{3}$ structure. Z. Naturforsch. B 50b, 619-622 (1995).

33. Zhang, S. B., Wei, S. H. \& Zunger, A. Microscopic origin of the phenomenological equilibrium 'doping limit rule' in $n$-type III-V semiconductors. Phys. Rev. Lett. 84, 1232-1235 (2000). 
34. Blöchl, P. E. Projector augmented-wave method. Phys. Rev. B 50, 17953-17979 (1994).

35. Perdew, J. P., Burke, K. \& Ernzerhof, M. Generalized gradient approximation made simple. Phys. Rev. Lett. 77, 3865-3868 (1996).

36. Heyd, J., Scuseria, G. \& Ernzerhof, M. Hybrid functionals based on a screened Coulomb potential. J. Chem. Phys. 118, 8207 (2003).

37. Krukau, A. V., Vydrov, O. A., Izmaylov, A. F. \& Scuseria, G. E. Influence of the exchange screening parameter on the performance of screened hybrid functionals. J. Chem. Phys. 125, 224106 (2006).

38. Kresse, G. \& Furthmüller, J. Efficient iterative schemes for $a b$ initio total-energy calculations using a plane-wave basis set. Phys. Rev. B 54, 11169-11186 (1996).

39. Kresse, G. \& Joubert, D. From ultrasoft pseudopotentials to the projector augmented-wave method. Phys. Rev. B 59, 1758-1775 (1999).

40. Hatada, N. CHESTA. Available at http://www.aqua.mtl.kyoto-u.ac.jp/ chestaEng.html (2010).

41. Jain, A. et al. Commentary: The Materials Project: a materials genome approach to accelerating materials innovation. APL Mater. 1, 011002 (2013).

42. Hedin, L. New method for calculating the one-particle Green's function with application to the electron-gas problem. Phys. Rev. 139, A796-A823 (1965).

43. Sanchez, J. M., Ducastelle, F. \& Gratias, D. Generalized cluster description of multicomponent systems. Phys. A 128, 334-350 (1984).

44. De Fontaine, D. in Cluster Approach to Order-Disorder Transformations in Alloys, in Solid State Phys Vol. 47, 33-176 (Academic Press, 1994).

45. Seko, A., Koyama, Y. \& Tanaka, I. Cluster expansion method for multicomponent systems based on optimal selection of structures for densityfunctional theory calculations. Phys. Rev. B 80, 165122 (2009).

46. Zunger, A., Wei, S. H., Ferreira, L. G. \& Bernard, J. E. Special quasirandom structures. Phys. Rev. Lett. 65, 353-356 (1990).

47. Freysoldt, C. et al. First-principles calculations for point defects in solids. Rev. Mod. Phys. 86, 253-305 (2014).

48. Freysoldt, C., Neugebauer, J. \& Van de Walle, C. G. Fully ab initio finite-size corrections for charged-defect supercell calculations. Phys. Rev. Lett. 102, 016402 (2009).

49. Kumagai, Y. \& Oba, F. Electrostatics-based finite-size corrections for first-principles point defect calculations. Phys. Rev. B 89, 195205 (2014).

50. Fukunaga, O., Ko, Y. S., Konoue, M., Ohashi, N. \& Tsurumi, T. Pressure and temperature control in flat-belt type high pressure apparatus for reproducible diamond synthesis. Diamond Relat. Mater. 8, 2036-2042 (1999).

51. Izumi, F. \& Momma, K. Three-dimensional visualization in powder diffraction. Solid State Phenom. 130, 15-20 (2007).

\section{Acknowledgements}

We thank Dr Atsuto Seko, Dr Hiroyuki Hayashi and Mr. Tomoyasu Yokoyama for the helpful discussions. This work was supported by the MEXT Elements Strategy Initiative to Form Core Research Center, Grants-in-Aid for Scientific Research B (grant no. 15H04125) and Scientific Research on Innovative Areas (grant nos 25106005 and 25106007) from JSPS, and Support Program for Starting Up Innovation Hub $\mathrm{MI}^{2} I$ from IST, Japan. L.A.B acknowledges support by a grant-in-aid for JSPS fellows (grant no. 26-04792). H.Hi. was supported by Support for Tokyotech Advanced Research (STAR). Computing resources of ACCMS at Kyoto University and TSUBAME2.5 at Tokyo Institute of Technology were used.

\section{Author contributions}

Y.H. carried out the calculations of electronic structures, thermodynamic and lattice dynamic stability, and alloy properties. Y.K. performed the point-defect calculations. L.A.B. conducted the structure search using the evolutionary algorithm technique. Y.H. F.O., Y.K., L.A.B. and I.T. analysed the theoretical data. T.H., H.S., Y.M., S.I., H.Hi. and H.Ho. performed the preparation and characterization of samples, and the analysis of experimental data. F.O. designed the research project. F.O. Y.H., and H.Hi. prepared the manuscript with the comments of all co-authors.

\section{Additional information}

Supplementary Information accompanies this paper at http://www.nature.com/ naturecommunications

Competing financial interests: The authors declare no competing financial interests.

Reprints and permission information is available online at http://npg.nature.com/ reprintsandpermissions/

How to cite this article: Hinuma, Y. et al. Discovery of earth-abundant nitride semiconductors by computational screening and high-pressure synthesis. Nat. Commun 7:11962 doi: 10.1038/ncomms11962 (2016).

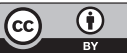

This work is licensed under a Creative Commons Attribution 4.0 International License. The images or other third party material in this article are included in the article's Creative Commons license, unless indicated otherwise in the credit line; if the material is not included under the Creative Commons license, users will need to obtain permission from the license holder to reproduce the material To view a copy of this license, visit http://creativecommons.org/licenses/by/4.0/ 